\title{
The criteria for evaluation of efficiency of heat technical installations considering general energy costs with the aim of increasing their environmental friendliness and reducing negative effect on the environment
}

\author{
Alexander Kulikov ${ }^{1, *}$, Irena Ivanova ${ }^{1}$ and Irina Russkova ${ }^{2}$, Jaromír Veber $^{3}$ \\ ${ }^{1}$ Institute of Technological Machines and Transport of the Wood, St. Petersburg State Forest Technical University of S.M. Kirov, \\ Institutsky Pr., 5, St. Petersburg, 194021, Russia \\ ${ }^{2}$ Higher School of Technospheric Safety, Peter the Great St. Petersburg Polytechnic University, Polytechnic Str., 29, St. Petersburg, \\ 195220, Russia \\ ${ }^{3}$ Czech Technical University, Prague, Czech Republic
}

\begin{abstract}
The features of the physical meaning of the thermal coefficient useful action (CUA) $\eta t$ as a criterion for the efficiency of reversible direct circular processes are considered. In particular, we demonstrate that accounting for all energy costs when applying $\eta t$ is made by adopting a number of assumptions by default. In order to expand the possibilities for conducting thermodynamic assessments of the efficiency of various thermal power plants, a new criterion of efficiency Ku is proposed as a coefficient that takes into account in a comparable form all types of energy spent on the implementation of the cycle. In determining the criterion $\mathrm{Ku}$, useful effect obtained from the implementation of a direct circular process is considered to be the specific work of the expansion of the working fluid in the cycle. Such work, in particular, can be the work of steam expansion in the turbine. The total energy cost is the sum of the specific heat supplied to the working body in a circular process and the specific mechanical work spent in the cycle on compression and pressure increase of the working body. In particular, the work is taken into account in a comparable form-taking into account the heat that was spent on its production. The analysis of the Ku criterion is carried out. As a result of the analysis we have established that at transition from the general physical model of reception of specific work of expansion in direct circular process for which Ku criterion can be applied, to the special case assuming a number of assumptions, Ku criterion can become equal to thermal coefficient useful action of a cycle. Using the Ku criterion, the efficiency of Carnot and Rankine cycles on a saturated pair is compared. The Ku score showed that the Rankine cycle was more efficient.
\end{abstract}

\section{Introduction}

In thermodynamics by means of reversible circular processes work of various heat technical installations (HTI), in particular internal combustion engines, steampower installations, refrigerators and thermal pumps is modeled [1, 2]. The efficiency of direct and return cycles decides on the help of various criteria [3, 4]. These criteria allow to choose the most effective which reduce the general fuel consumption from a number of options of technical solutions, so, provide big environmental friendliness of processes $[5,6]$.

When determining criterion of efficiency of any heat technical installation two additional concepts are entered, as a rule: useful effect and costs of realization of the process providing achievement of useful effect [7-9]. Usually understand quantitatively certain result achieved thanks to heat technical installation according to the destination as useful effect. Expenses usually are understood as the sum of all or main resources necessary for a possibility of achievement of useful effect on this heat technical installation. In that case the criterion of efficiency can be defined as the relation of useful effect to expenses [10, 11].

In various heat technical installations useful effects can differ very $[12,13]$. So, for example, for heat treatment furnaces as useful effect the amount of heat brought to a working body - the gas mix moving in the operating volume of the furnace which provides performance of a necessary condition of successful heat treatment of material can be accepted - increases temperature of a working body to the required level [14].

Traditionally in thermodynamics the efficiency of direct circular processes is estimated by means of the thermal coefficient useful action (CUA) $\eta_{t}$. When determining $\eta_{t}$ as useful effect specific work of all cycle $l_{\text {cyc }}$, and as expenses - the warmth of $q_{\mathrm{br}}$ brought to a working body in a cycle is considered:

* Corresponding author: ltuttsu@mail.ru 


$$
\eta_{t}=\frac{l_{\mathrm{cyc}}}{q_{\mathrm{br}}}
$$

\section{Methods}

The basic method is the theoretical analysis of the efficiency of reversible circular processes. This method provides a comparative analysis of the effectiveness of direct cycles. The method is based on the adoption of the following provisions. The thermodynamic result of a direct circular process is that the thermodynamic system, in which the cycle is realized, is supplied with energy from the environment in the form of heat $q_{\text {bri }}$, and the system transfers to the environment a certain amount of energy in the form of mechanical work $l_{\text {cyc }}$ and a certain amount of energy in the form of heat $q_{\text {wi }}$. In the process of heat supply to the system, the temperature of the system is higher than in the process of heat removal. In the course of any cycle, the working body in some parts of it performs the work of expansion, in others compression. The total work of the cycle will be equal to the difference between the total work for the cycle of expansion $l_{\mathrm{ex}}$ and the total work of compression $l_{\mathrm{com}}$ :

$$
l_{\mathrm{cyc}}=l_{\mathrm{ex}}-l_{\mathrm{com}} .
$$

From (2) follows the following position, underlying the proposed method: for the implementation of a direct circular process is necessary to supply the working body from the environment, not only energy in the form of heat $q_{\mathrm{br}}$, but also in the form of mechanical work to compress the working body $l_{\text {com }}$. At the same time, from the traditional formula (1) for thermal coefficient useful action, it follows that only the costs of energy supplied to the working body in the form of heat $q_{\text {br }}$ are taken into account as energy costs. In this case, the cost of mechanical energy for compression is taken into account as follows. By default, it is assumed that a part of the mechanical energy of the expansion $l_{e x}$ performed by the working body is somehow conserved in the environment during this expansion. After the expansion has been completed and the compression has begun, this mechanical energy, preserved in the environment, is brought to the working body without loss in some way by means of some devices. As a result, the necessary compression of the working fluid in the circular process is provided and the work of compression of the $l_{\text {com }}$ is performed. Thus, all the work of the $l_{e x}$ expansion is somehow divided into two parts: one is transferred to the environment for free use, the second is first conserved and then, when the time comes, used to compress the working body. The proposed method of analysis allows estimating the efficiency of a direct circular process to take into account all types of energy costs, without involving any additional assumptions.

\section{Results}

In a number of cases, the implementation of direct circular processes, for example, in steam-power installation (SPI), in which to increase the pressure of the working fluid consumes electrical energy supplied to the drive of the feed pump, the above traditional scheme of assumptions is not strictly fulfilled [15]. In such cases, it is advisable to be able to evaluate the effectiveness of direct cycles without introducing the preliminary assumptions described above. This purpose can be used a new criterion of efficiency, in which the useful effect is considered all the work expansion of the working fluid $l_{e x}$, and as cost - the total cost of implementing a cycle consisting of two types of energy conducted to the working fluid from the environment in the form of heat $q_{\text {bri }}$ in the form of mechanical work to compress the working fluid $l_{\text {com }}$. Such criterion of efficiency should be called the coefficient considering all costs and to designate as $\mathrm{Ku}$.

That in circular process comparably to put energy in the form of warmth $q_{\mathrm{br}}$ and energy in the form of mechanical work of $l_{\text {com }}$ it is necessary to consider nonequivalence of warmth and work. In any heat engine, as we know, only a part from the brought warmth turns into mechanical work. For comparable addition of $q_{\mathrm{br}}$ and $l_{\text {com }}$ it is expedient to accept that the auxiliary heat engine located in the environment is used to implementation of compression of a working body. Operation of such engine is also modeled by means of a direct cycle. In this cycle warmth $q_{\mathrm{br}}^{\prime}$ is failed to a working body, work of expansion $l_{\mathrm{ex}}^{\prime}$ and compression $l_{\text {com }}^{\prime}$

$l_{\text {com }}$ of a working body are made. Thus, work of $l_{\text {com }}$ in an initial direct cycle is made, generally, at the expense of a part of operation $l_{\mathrm{ex}}^{\prime}$ of the auxiliary engine. The total costs of warmth of $1 \mathrm{~J} / \mathrm{kg}$ of work $l_{\mathrm{ex}}^{\prime}$ in the auxiliary engine make:

$$
\Delta=\frac{q_{\mathrm{br}}^{\prime}+l_{\mathrm{com}}^{\prime} \cdot \Delta^{\prime}}{l_{\mathrm{ex}}^{\prime}},
$$

where $\Delta$ and $\Delta^{\prime}-$ is the total costs of specific heat in cycles on $1 \mathrm{~J} / \mathrm{kg}$ of specific works of $l_{\text {com }}$ and $l_{\text {com }}^{\prime}$ respectively.

Due to introduction to (3) sizes $\Delta^{\prime}$ the nonequivalence of warmth $q_{\mathrm{br}}^{\prime}$ and work $l_{\text {com }}^{\prime}$ at their addition is considered.

As a result the general expression for the coefficient considering all costs of realization of direct circular process, Ku takes a form:

$$
\mathrm{Ku}=\frac{l_{\mathrm{ex}}}{q_{\mathrm{br}}+l_{\mathrm{com}} \cdot\left(\frac{q_{\mathrm{br}}^{\prime}+l_{\mathrm{com}}^{\prime} \cdot \Delta^{\prime}}{l_{\mathrm{br}}^{\prime}}\right)} .
$$

Strictly speaking, by drawing up thermodynamic models of operation of power stations for the general case, size $\Delta$ and $\Delta^{\prime}$ are not equal. For the analysis of 
properties of criterion of $\mathrm{Ku}$ will let's assume their equality. Let's also in addition accept that the following sizes are equal among themselves: $q_{\mathrm{br}}=q_{\mathrm{br}}^{\prime}$, $l_{\text {com }}=l_{\text {com }}^{\prime}, l_{\mathrm{ex}}=l_{\mathrm{ex}}^{\prime}$. As a result of it (3) it is possible to write down in a look:

$$
\Delta=\frac{q_{\mathrm{br}}+l_{\mathrm{com}} \cdot \Delta}{l_{\mathrm{ex}}} .
$$

From (5) we receive:

$$
\Delta=\frac{q_{\mathrm{br}}}{l_{\mathrm{ex}}-l_{\text {com }}} .
$$

Substituting (6) in (4) for the considered special case providing a number of the assumptions described above, we receive expression:

$$
\begin{aligned}
& \mathrm{Ku}^{\mathrm{AS}}=\frac{l_{\mathrm{ex}}}{q_{\mathrm{br}}+l_{\mathrm{com}} \cdot \frac{q_{\mathrm{br}}}{\left(l_{\mathrm{ex}}-l_{\mathrm{com}}\right)}}= \\
& =\frac{l_{\mathrm{ex}}-l_{\mathrm{com}}}{q_{\mathrm{br}}}=\frac{l_{\mathrm{cyc}}}{q_{\mathrm{br}}}=\eta_{t}
\end{aligned}
$$

where $\mathrm{Ku}^{\mathrm{AS}}$ - value of criterion $\mathrm{Ku}$ at the assumptions made for the considered special case.

From (7) follows that at the assumptions made upon transition from the general to the particular to the case considered above the coefficient considering all expenses becomes equal to the thermal coefficient useful action of a direct cycle which can be determined by a formula:

$$
\eta_{t}=\frac{l_{\mathrm{ex}}}{q_{\mathrm{br}}+l_{\mathrm{com}} \cdot \frac{q_{\mathrm{br}}}{\left(l_{\mathrm{ex}}-l_{\mathrm{com}}\right)}},
$$

From (8) follows that when determining thermal coefficient useful action of a direct cycle, as useful effect work expansion of a working body of $l_{\mathrm{ex}}$, and as expenses the sum of all types of the energy brought for realization of a cycle in a comparable form can be taken over. And by such comparison it is assumed that for 1 $\mathrm{J} / \mathrm{kg}$ of work of $l_{\text {com }}$ it is spent as much warmth, how many for $1 \mathrm{~J} / \mathrm{kg}$ of work of all cycle $l_{\text {сус }}$. It should be noted that without consideration of logic of transition from the general case (4) to private (7), the last assumption cannot be considered as strictly reasonable.

For the specific conditions which are found in various HTI, expression for criterion of $\mathrm{Ku}$ can take a different form [16]. For a reversible cycle by means of which work of steam-power installation is modeled work of a cycle, as we know, can be determined by formula:

$$
l_{\mathrm{cyc}}^{\mathrm{SPI}}=l_{\mathrm{tur}}-l_{\mathrm{pu}},
$$

where $l_{\text {cec }}^{\text {SPI }}$ specific work of a cycle of steam-power installation, $\mathrm{J} / \mathrm{kg} ; l_{\mathrm{tur}}$ and $l_{\mathrm{pu}}-$ specific theoretical technical operation of the turbine and the pump providing the required pressure of feed water, $\mathrm{J} / \mathrm{kg}$.

Proceeding from (9), when determining for steampower installation of criterion of efficiency for the general case on type (4), as useful effect technical work the turbine $l_{\text {tur }}$, and as all expenses - the sum of the warmth brought in a cycle to a working body $q_{\mathrm{br}}^{\text {SPI }}$ and the technical work of $l_{\mathrm{pu}}$ spent during the operation of the pump, in a comparable form is taken over:

$$
\mathrm{Ku}^{\mathrm{SPI}}=\frac{l_{\mathrm{tur}}}{q_{\mathrm{br}}^{\mathrm{SPI}}+l_{\mathrm{pu}} \cdot \Delta^{\mathrm{pu}}},
$$

where $\mathrm{Ku}^{\mathrm{SPI}}$ - is the effectiveness ratio considering all main costs of energy of implementation of a reversible cycle of steam-power installation; $\Delta^{\mathrm{pu}}$ - the total costs of specific heat in a cycle falling on $1 \mathrm{~J} / \mathrm{kg}$ of specific operation of the pump $l_{\mathrm{pu}}$.

Quantity $\Delta^{\mathrm{pu}}$, by analogy with (3), is on a formula:

$$
\Delta^{\mathrm{pu}}=\frac{q_{\mathrm{br}}^{\prime \mathrm{SPI}}+l_{\mathrm{com}}^{\prime \mathrm{pu}} \cdot \Delta^{\prime \mathrm{pu}}}{l_{\mathrm{ex}}^{\prime \mathrm{pu}}},
$$

where $q_{\mathrm{br}}^{\text {SPI }}$ - the specific heat brought to a working body in the cycle modeling operation of the auxiliary engine ensuring functioning of the pump, J/kg; $l_{\text {com }}^{\prime \text { pu }}$ and $l_{\mathrm{ex}}^{\prime \mathrm{pu}}$

- specific works of compression and expansion of a working body in a cycle of the auxiliary engine, $\mathrm{J} / \mathrm{kg}$; $\Delta^{\prime \mathrm{pu}}$

- the total costs of specific heat in a cycle of the auxiliary heat engine falling on $1 \mathrm{~J} / \mathrm{kg}$ of specific work $l_{\mathrm{com}}^{\prime \mathrm{pu}}$.

Having accepted as assumptions the additional conditions similar to considered above about what $q_{\mathrm{br}}^{\mathrm{SPI}}=q_{\mathrm{br}}^{\mathrm{SPI}}, \quad l_{\mathrm{pu}}=l_{\mathrm{com}}^{\prime \mathrm{pu}}, \quad l_{\mathrm{tur}}=l_{\mathrm{ex}}^{\prime \mathrm{pu}}$, $\Delta^{\mathrm{pu}}=\Delta^{\mathrm{pu}}$ , from the expressions (10) and (11) defining criterion of $\mathrm{Ku}^{\text {SPI }}$ for the general case it is possible to receive for this special case:

$$
\begin{aligned}
& \mathrm{Ku}^{\mathrm{SPI} A \mathrm{~S}}=\frac{l_{\mathrm{tur}}}{q_{\mathrm{br}}^{\mathrm{SPI}}+l_{\mathrm{pu}} \cdot \frac{q_{\mathrm{br}}^{\mathrm{SPI}}}{\left(l_{\mathrm{tur}}-l_{\mathrm{pu}}\right)}}, \\
& =\frac{l_{\mathrm{tur}}}{q_{\mathrm{br}}^{\mathrm{SPI}}+l_{\mathrm{pu}} \cdot \frac{1}{\eta_{t}^{\mathrm{SPI}}}}=\eta_{t}^{\mathrm{SPI}}
\end{aligned}
$$


where $\mathrm{Ku}^{\text {SPI AS }}-$ criterion of $\mathrm{Ku}^{\mathrm{SPI}}$ at the accepted assumptions; $\eta_{t}^{\text {SPI }}$ - thermal efficiency of steam-power installation.

Equation (12) shows that in the considered above particular case, the thermal coefficient useful action of steam power plant will be equal to the criterion for $\mathrm{Ku}$, taking into account all comparable energy costs for the implementation cycle plants.

Let us consider the practical application of the $\mathrm{Ku}$ criterion by comparing the performance of a steam power plant on two different cycles in the same temperature range: the Renkine cycle on saturated steam and the Carno cycle on saturated steam. It is known that if we evaluate the efficiency of these cycles using thermal efficiency, the Carno cycle is more effective. At realization of such cycle of Carno mechanical energy in the quantity corresponding about $55 \%$ of the turbine energy is spent for the drive of the compressor $[17,18]$. It can be shown that when evaluating the effectiveness of these cycles using the Ku criterion, the opposite result is obtained.

Let's accept for assessment the temperature range in which cycles from 25 to $350^{\circ} \mathrm{C}$ are implemented, we will consider Operation of the turbine $l_{\text {tur }}$ in both cycles identical. A condition of the preference of a cycle of Renkin's over Carno's cycle written as:

$$
\mathrm{Ku}^{\mathrm{R}}>\mathrm{Ku}^{\mathrm{C}} \text {, }
$$

where $\mathrm{Ku}^{\mathrm{R}}$ and $\mathrm{Ku}^{\mathrm{C}}$ - the coefficients considering everything the costs of realization of cycles in a comparable form calculated for Renkin's and Carno's cycle, respectively.

From (13), taking into account (10), it turns out:

$$
q_{\mathrm{br}}^{\mathrm{R}}+l_{\mathrm{pu}}^{\mathrm{R}} \cdot \Delta^{\mathrm{R}}<q_{\mathrm{br}}^{\mathrm{C}}+l_{\mathrm{c}}^{\mathrm{C}} \cdot \Delta^{\mathrm{C}},
$$

where $q_{\mathrm{br}}^{\mathrm{R}}$ and $q_{\mathrm{br}}^{\mathrm{C}}$ - the specific warmth brought to a working body in Renkin's and Carno's cycles, respectively, $\mathrm{J} / \mathrm{kg} ;{ }_{\mathrm{pu}}^{\mathrm{R}}$ - specific operation of the pump in Renkin's cycle, $\mathrm{J} / \mathrm{kg} ;{ }_{\mathrm{c}}^{\mathrm{C}}-$ specific operation of the compressor in Carno's cycle, J/kg; $\Delta^{\mathrm{R}}$ and $\Delta^{\mathrm{C}}$ - the total costs of specific heat in cycles falling on $1 \mathrm{~J} / \mathrm{kg}$, specific operation of the pump $l_{\mathrm{pu}}^{\mathrm{R}}$ (in Renkin's cycle) and the compressor $l_{\mathrm{c}}^{\mathrm{C}}$ (in Carno's cycle).

When determining sizes $\Delta^{\mathrm{R}}$ and $\Delta^{\mathrm{C}}$ it is also considered that the pump in Renkin's cycle has the coefficient useful action $-\eta_{\mathrm{pu}}$, and the compressor in Carno's cycle has the coefficient useful action $-\eta_{\mathrm{c}}$.

Operation of drives at the pump and the compressor is carried out at the expense of the electric energy brought to them which is developed, for example, on the turbine plant with absolute electric coefficient useful action $\eta_{\text {TPE. }}$. As a result we receive:

$$
\Delta^{\mathrm{R}}=\frac{1}{\eta_{\mathrm{pu}}} \cdot \frac{1}{\eta_{\mathrm{TPE}}} \quad \Delta^{\mathrm{C}}=\frac{1}{\eta_{\mathrm{c}}} \cdot \frac{1}{\eta_{\mathrm{TPE}}}
$$

For confirmation of justice of inequality (14) we will carry out its assessment. For assessment it is possible to accept that $\eta_{\mathrm{pu}}=\eta_{\mathrm{c}}=1 ; \eta_{\mathrm{TPE}}=0,4 ; l_{\mathrm{c}}^{\mathrm{C}}=0,5 l_{\text {tur }} ; l_{\mathrm{pu}}^{\mathrm{R}}=$ $0,1 l_{\text {tur. }}$ As a result from (14) we receive:

$$
q_{\mathrm{br}}^{\mathrm{R}}-q_{\mathrm{br}}^{\mathrm{C}}<l_{\mathrm{tur}} .
$$

In the considered range the thermal coefficient useful action of a cycle of Carnot $\eta_{t}^{\mathrm{C}}$ will is equal 0,52, therefore, we can write down:

$$
\eta_{t}^{\mathrm{SPI}}=\frac{l_{\mathrm{cyc}}^{\mathrm{C}}}{q_{\mathrm{br}}^{\mathrm{C}}} \cdot \frac{q_{\mathrm{br}}^{\mathrm{C}}-q_{\mathrm{re}}^{\mathrm{C}}}{q_{\mathrm{br}}^{\mathrm{C}}}=\frac{l_{\mathrm{tur}}-l_{\mathrm{c}}^{\mathrm{C}}}{q_{\mathrm{br}}^{\mathrm{C}}}=0,52,
$$

where $q_{\mathrm{re}}^{\mathrm{C}}-$ the specific taken-away heat in Carno's cycle, $\mathrm{J} / \mathrm{kg}$.

Taking into account the assumptions made above from (17) we receive:

$$
l_{\mathrm{tur}}=1,04 \cdot q_{\mathrm{br}}^{\mathrm{C}} \text {. }
$$

Substituting (18) in (16) we receive:

$$
q_{\mathrm{br}}^{\mathrm{R}}<2,04 \cdot q_{\mathrm{br}}^{\mathrm{C}} .
$$

It is easy to be convinced that inequality (19) is carried out.

\section{Discussion}

Comparison of efficiency of cycles on criterion of $\mathrm{Ku}$ shows that Carno's cycle in this case is less preferable not only because the compressor for compression of the wet vapor having large specific volume is the bulky construction difficult in terms of operation, but also because taking into account all power expenses it is less favorable.

Thus, transition in work of steam-power installations from Carno's cycle on saturated steam on Renkin's cycle on saturated steam, when using criterion of $\mathrm{Ku}$, become more reasonable.

The possibility of increase in validity of the choice of rational technical solutions in the field of the heat power equipment increases, eventually, overall effectiveness of use of different types of fuel [19, 20]. And it, in turn, leads to decrease in specific values of harmful emissions in many technological processes on a number of indicators [21], ensuring a reduction of environmental pressures on the environment [22, 23, 24]. Thus:

1. For expansion of opportunities when carrying out thermodynamic estimates of efficiency of heat power installations the new criterion of $\mathrm{Ku}$ considering as 
expenses different types of the energy brought to a working body in a comparable form is offered.

2. A certain connection between the offered criterion of $\mathrm{Ku}$ and thermal coefficient useful action of a direct cycle $\eta_{t}$ is established.

3. Increase in validity of the choice of technical solutions cuts volumes of fuel consumption and provides environmental friendliness of processes due to reducing of contamination, including the thermal one [25].

\section{References}

1. P.A. Berezinets, G. G. Olkhovsky Gas-turbine and combined cycle gas turbines, In the collection: Modern nature protection technologies in power industry, 273-292 (2007).

2. Yu.V. Vikhrev, Prospects of development of thermal power. Journal of Energy, economy, equipment, ecology, 10-14 (2012).

3. Yu.B. Barkovsky, E.N. Moos, N.I. Tabunova, Effeciency of the return cycles, Journal of Technical physics, 11-14 (1999).

4. V. A. Kirillin, Engineering thermodynamics, Textbook, 495 (2008)

5. A.P. Byzov, A.I. Shershneva, M.A. Ens, Assessment Methodology for Personal Risk Assessment in the Field of Waste Storage, Proceedings of the 2018 IEEE International Conference "Management of Municipal Waste as an Important Factor of Sustainable Urban Development", WASTE 2018, the article № 8554146, 49-51 (2018)

6. N.V. Rumyantseva, A.S. Doronin, E.A. Primak Improvement of the System of Selective Collection of Household Waste in Latvia, Proceedings of the 2018 IEEE International Conference "Management of Municipal Waste as an Important Factor of Sustainable Urban Development", WASTE 2018, the article № 8554105, 60-62 (2018)

7. B.M. Troyanovsky, A.P. Cucumbers, Domestic steam turbines. State, prospects of development, Journal of Power system, 2-9 (1998).

8. G.A. Rasponin, Increase in efficiency of condensation heat power systems, Journal of News of higher educational institutions. Construction, 110-113 (2003)

9. S.D. Haydarov, Zh.H. Abdubannayev, Sh.Sh. Rustamova, Use of the combined combined cycle gas turbines as perspective sources of electric energy, Journal of Infrastructure branches of economy: problems and prospects of development, 214-222 (2016)

10. V.V. Slesarenko, To determination of thermodynamic efficiency of the cogeneration Installations, Journal of Energy saving and water treatment, 36-38 (2010)

11. I.S. Trokhin, Comments on scientific publications about steam engines in small-scale power generation, Journal of Works of the international scientific and technical conference power supply and energy saving in agriculture, 138-142 (2014)

12. O.K. Bezyukov, V.A. Zhukov, O.I. Yashchenko, Analysis of perspective gas-piston DVS, Journal of Internal combustion engines, 45-51 (2014)

13. P.A. Berezinets, G. G. Olkhovsky, Gas-turbine and combined cycle gas turbines, Collection of scientific works Modern nature protection technologies in power industry, 272-292 (2007)

14. A. A. Kulikov, Optimization of thermal work hightemperature shatnykh of furnaces, Collection of scientific works Metallurgical heating engineer, 116-118 (1999)

15. G.Sh. Piralishvili, S.V. Veretennikov, Thermodynamic analysis of schemes of power stations, Journal of Bulletin of the Rybinsk state aviation technological academy of P.A. Solovyov, 154-160 (2011)

16. V. Burov, A. Dudolin, E. Oleynikova, On the agenda - the efficiency of thermal power plant, Journal of Power supervision, 25-27 (2015)

17. N. I. Prokopenko, Bases of the theory of thermal processes Education manual, 571 (2011)

18. N.N. Rudenko, Steam-gas technology in power, Journal of the world of discoveries, 88-91 (2010)

19. P.M. Kanilo, A.P. Marchenko, I.V. Parsadanov, Thermal power, DVS and global warming of climate, Journal of Internal combustion engines, 5768 (2015)

20. A.N. Kondratenko, The concept of assessment of effective management of environmental safety of process of operation of power stations with piston DVS, Journal of Internal combustion engines, 68-72 (2016)

21. I.G. Russkova, V.P. Malyshev, Environmental safety, Lecture course, Peter the Great Saint Petersburg Polytechnic University (2018)

22. V.M. Borovkov, L.V. Zysin, V.V. Sergeev, The totals and technological problems of usage of vegetative biomass and organic waste in power engineering Izvestiya Akademii Nauk, Energetika 6 13-24 (2002)

23. E.P. Istomin, V.M. Abramov, V.G. Burlov, A.G. Sokolov, N.N. Popov, Development of technology for environmental safety control based on geoinformation systems International Multidisciplinary Scientific GeoConference Surveying Geology and Mining Ecology Management, SGEM 17(21) 859866, DOI: 10.5593/sgem2017/21/S08.109 (2017)

24. E.P. Istomin, V.M. Abramov, A.A. Fokicheva, A.G. Sokolov, V.G. Burlov, New approach to the assessment of geohazard in the management of the territories International Multidisciplinary Scientific GeoConference Surveying Geology and Mining Ecology Management, SGEM 17(21) 1005-1012 DOI: 10.5593/sgem2017/21/S07.127 (2017)

25. A. Bril, O. Kalinina, A. Kankovskaya, V. Vilken, Operational risk management in financing 
environmental activities and personnel management projects, E3S Web of Conferences 110 02018, DOI: 1051/e3sconf/201911002018 (2019) 